\title{
BMJ Global Health Does foreign aid crowd out government investments? Evidence from rural health centres in Rwanda
}

\author{
Chunling Lu, ${ }^{1,2}$ Benjamin Cook, ${ }^{3}$ Chris Desmond ${ }^{4}$
}

To cite: Lu C, Cook B, Desmond C. Does foreign aid crowd out government investments? Evidence from rural health centres in Rwanda. BMJ Glob Health 2017;2:e000364. doi:10.1136/ bmjgh-2017-000364

- Additional material is published online only. To view please visit the journal online (http://dx.doi.org/10.1136/ bmjgh-2017-000364).

Received 8 April 2017 Revised 30 June 2017 Accepted 3 July 2017

\section{(a) CrossMark}

'Division of Global Health Equity, Brigham and Women's Hospital, Harvard Medical School, Boston, Massachusetts, USA

${ }^{2}$ Department of Science and Technology-National Research Foundation (DST-NRF) Center of Excellence in Human Development, University of Witwatersrand, Johannesburg, South Africa

${ }^{3}$ Department of Psychiatry, Harvard Medical School, Cambridge Health Alliance, Cambridge, Massachusetts, USA ${ }^{4}$ Human and Social Development Research Programme, Human Sciences Research Council, Durban, South Africa

Correspondence to

Dr Chunling Lu;

chunling_lu@hms.harvard.edu

\section{ABSTRACT}

Background Rural healthcare facilities in low-income countries play a major role in providing primary care to rural populations. We examined the link of foreign aid with government investments and medical service provision in rural health centres in Rwanda.

Methods Using the District Health System Strengthening Tool, a web-based database built by the Ministry of Health in Rwanda, we constructed two composite indices representing provision of (1) child and maternal care and (2) HIV, tuberculosis (TB) and malaria services in 330 rural health centres between 2009 and 2011. Financing variables in a healthcare centre included received funds from various sources, including foreign donors and government. We used multilevel random-effects model in regression analyses and examined the robustness of results to a range of alternative specification, including scale of dependent variables, estimation methods and timing of aid effects.

Findings Both government and foreign donors increased their direct investments in the 330 rural healthcare centres during the period. Foreign aid was positively associated with government investments $(0.13,95 \% \mathrm{Cl} 0.06$ to $0.19)$ in rural health centres. Aid in the previous year was positively associated with service provision for child and maternal health $(0.008,95 \% \mathrm{Cl} 0.002$ to 0.014$)$ and service provision for HIV, TB and malaria $(0.014,95 \% \mathrm{Cl}$ 0.004 to 0.022$)$ in the current year. The results are robust when using fixed-effects models.

Conclusions These findings suggest that foreign aid did not crowd out government investments in the rural healthcare centres. Foreign aid programmes, conducted in addition to government investments, could benefit rural residents in low-income countries through increased service provision in rural healthcare facilities.

\section{INTRODUCTION}

In low-income countries, rural healthcare facilities are the major primary care provider for rural populations. Building well-functioning rural healthcare centres is, therefore, crucial for achieving universal healthcare in resource-poor settings. The delivery of quality care requires policy makers to ensure a sufficient and sustainable flow of funding to rural healthcare facilities.

\section{Key questions}

What is already known about this topic?

- Previous empirical studies on health aid effects have been conducted at the global, regional or country levels.

- Health aid was found to be effective in increasing the coverage of vaccines in developing countries and to crowd out domestic public spending on health in studies aggregating data from countries in the subSaharan Africa region.

- Existing literature offered little empirical evidence on how health aid interplays with government health spending and medical service coverage at the health facility level.

\section{What are the new findings?}

- In rural health centres in Rwanda, an increase in foreign aid at the health facility level did not crowd out government investments and was positively associated with service provision for child and maternal care and infectious diseases.

- Foreign aid in the previous year could significantly affect the supply of health services in the current year in rural areas when it was additional to government investments.

\section{Recommendations for policy}

- Integrating aid, government investments and other funding sources is crucial for improving service availability in rural healthcare centres. Ensuring aid additionality should be given high priority when designing policy instruments for achieving aid effectiveness.

- To help both donors and governments to effectively coordinate on budgeting, and monitoring and evaluating aid performance, donors should provide financial and technical assistance to recipient countries in developing data tracking systems for resources and service provision at the local healthcare facility level.

To support low-income countries to meet the health-related Millennium Development Goals (MDGs), starting in 2000, there was a sharp increase in foreign aid to health sectors in low-income countries. ${ }^{1}$ As a consequence, foreign aid has accounted for a large portion 
of total health spending in many of these countries. According to the Global Health Expenditure Database maintained by the WHO, as of 2013, health aid made up $20 \%-69 \%$ of total health expenditures in the 26 least-developed sub-Saharan countries. ${ }^{1}$

At the same time as aid has been increasing, many low-income countries have been undergoing health sector reform. This has typically led to the decentralisation of healthcare financing and decision making to local healthcare facilities. ${ }^{2-4}$ As a result of these reforms, external health aid flows into these countries at both central and local levels.

Understanding the effect of health aid on health system strengthening and population health outcomes has profound policy importance. The debates over aid effectiveness need to be furnished with sound evidence. Previous studies on health aid have mainly focused on its levels, trends, purposes and effects at the global, regional and country levels. ${ }^{5-14}$ Such studies have addressed issues such as the ability of countries to absorb aid ${ }^{5}$ and the effect of aid on selected outcomes, such as coverage of diphtheria, tetanus and pertussis vaccines in developing countries. ${ }^{6}$ One of the most contentious issues identified in the literature is the interaction between foreign aid and governments' resource allocations to their health sectors, specifically the extent to which aid 'crowds out' government spending (leads governments to divert resources elsewhere). Previous studies suggest that the extent of crowding out is often determined by the type of aid. For example, one study found that, between 1995 and 2006, external health aid in sub-Saharan Africa was fungible; that is, the recipient governments substituted their resource allocation to the health sector with foreign health aid. ${ }^{7}$ Conversely, a country-level study showed that aid for HIV was additional to government spending on HIV programmes in Rwanda, Thailand and Honduras. ${ }^{8}$

One of the limitations of the previously conducted cross-national or country-level analyses is that the estimated effect is an average across a heterogeneous set of countries or subnational areas and does not provide evidence on how aid contributed to healthcare facilities that directly deliver medical services to the populations on a daily basis. Our literature search yielded very limited empirical evidence at the subnational level. ${ }^{15}$ This study used data gathered from rural health centres in Rwanda to investigate two research questions: (1) Did government investments in rural healthcare centres increase or remain the same as the external aid flowed in; and (2) Is the inflow of aid linked with increasing service provision in rural healthcare centres.

\section{Background on Rwanda and its health system}

Rwanda is an agricultural country in central and east Africa with a gross domestic product per capita of US $\$ 690$ in $2015 .{ }^{16}$ In 2014 , the country had an estimated 12 million inhabitants, $83 \%$ of whom lived in rural areas. ${ }^{17}$ It has four provinces and its capital Kigali City, 30 districts and 416 sectors (subdistricts). ${ }^{18}$ The genocide in 1994 set Rwanda back in every regard. However, since 2000, the country has made impressive progress in its social and economic development, including improving health outcomes. For example, the under-five child mortality rate fell drastically from 196 per 1000 live births in 2000 to 50 per 1000 live births in $2015,{ }^{19}$ making Rwanda one of only a few sub-Saharan countries that met the MDG target related to reducing child mortality. ${ }^{20}$

The health system in Rwanda is organised in three tiers: national referral hospitals (tertiary), district hospitals (secondary) and health centres (primary). There are three types of health facilities: government-owned facilities, public facilities owned by faith-based organisations (FBOs) or non-governmental organisations (NGOs) and private, for-profit facilities. Facilities owned by FBOs or NGOs are recognised by the Ministry of Health $(\mathrm{MoH})$ as a part of the public health sector and follow the norms and standards of the public sector. ${ }^{21}$ In 2014, approximately $15 \%$ of public health facilities in Rwanda were owned by NGOs and FBOs, and most of these were rural health centres. ${ }^{22}$ The private sector is relatively small and includes for-profit private clinics (based in urban areas) and traditional healers. ${ }^{21}$

In Rwanda, the majority of the population accesses care via the public health sector. Health centres are required to provide essential services, ranging from promotion (eg, campaigns on HIV, tuberculosis (TB) and malaria), prevention (eg, vaccination, nutrition, testing for HIV and prenatal and postnatal consultation), to treatment (eg, HIV or TB or malaria care, nutritional rehabilitation and birth delivery).$^{21}$ In practice though, many rural health centres do not have the capacity to provide all required services. ${ }^{23}$

A substantial disparity has been found in health outcomes and health service availability between rural and urban areas in Rwanda. For example, stunting prevalence among children 5 years or younger was $47 \%$ in rural areas and $27 \%$ in urban areas. ${ }^{24}$ Residents in Kigali City enjoy better access to quality care than do rural residents: all national referral hospitals and private clinics are located in the city.

To achieve universal healthcare, one of the priorities of the Government of Rwanda (GoR) is to improve availability and quality of care in rural healthcare centres. ${ }^{25}$ In pursuit of this goal, the government has, since 2006, adopted a decentralised healthcare financing policy, which gives managerial autonomy to health centres. Decentralisation opens up the possibility of a relatively significant change in financial flows in rural healthcare facilities: rural healthcare centres receive funds (in cash or in-kind support) directly from external donors. ${ }^{21}$ As a low-income country, Rwanda has relied heavily on foreign health aid: the percentage of total health spending financed by foreign aid peaked in 2009 at $67 \%$ and remained high at $54 \%$ in $2013 .{ }^{1}$ It is critically important to understand the effect of allowing some of the aid to flow directly to health facilities. 


\section{METHODS}

\section{Data and sample}

We used the 2009-2011 data of the District Health System Strengthening Tool (DHSST), a web-based database built by the Rwandan $\mathrm{MoH}$, to collect annual financial and service data from health centres and district hospitals in the public sector. ${ }^{26}$ Starting from 2009, the DHSST posted an online standardised survey tool that allows accountants in the health facilities to log into the online survey and report the following items on an annual basis: (1) medical services provided, (2) capacity building (infrastructure and staffing), (3) annual funds received (from different sources) and (4) demographic and geographical information in its catchment areas. Although the online reporting system is a useful channel for gathering data from health centres, the DHSST was not effective in capturing the value of in-kind financial support (donated goods and services) received by the health centres. ${ }^{27} \mathrm{We}$ therefore focused on total received funds as cash flows in health centres. In a previous unpublished study, we compared cash flow data in health centres of one rural district gathered from two different sources: the DHSST and the data gathered using an established five-step procedure proposed in a published study. ${ }^{27}$ We found that although the DHSST tends to under-report the cash flows in these health centres, the correlation of the two sets of data is 0.74 .

In the DHSST, there is a variable indicating if a health centre is situated in Kigali City or one of the four provinces outside of Kigali City. Per standard procedures used in Rwanda, Kigali City is considered to be an urban area and all other provinces rural. Because we wanted to focus on rural healthcare provision, we excluded health centres located in Kigali City but kept all of the remaining health centres. There were 393, 401 and 407 rural health centres in 2009, 2010 and 2011, respectively. ${ }^{28}$ To conduct panel data analysis, we included rural health centres (owned either solely by the government or operated in partnership with FBOs or NGOs), which appeared in the financial data in all 3 years (370). We excluded 10 health centres that reported missing data in foreign aid or government investments. After consulting with Rwanda colleagues, we excluded those health centres that reported extremely small or large values of total received funds that could be due to reporting error: below US\$5000 (7) or above US $\$ 500000$ (17) in one of the 3years. The reported values of those health centres were either above the 99th percentile or below the second percentile of the 370 health centres. To test the robustness of our analysis, we also conducted the analysis by including the health centres with these extreme values, and the main results stayed the same. In addition, we excluded those health centres (6) with missing information in percentage of indigent population in their catchment areas. The final sample size is 990 rural health centres with 330 rural health centres in each year.

\section{Measuring service provision}

Two types of service provision were examined in the analysis: (1) service provision for child and maternal care and (2) service provision for infectious diseases (HIV, TB and malaria). We measured them by identifying a list of binary variables from the DHSST that indicates if a health centre did or did not provide a specific relevant service (online supplementary appendix table 1). The DHSST surveys included 67 binary variables on services related to child and maternal health and 31 binary variables on services for HIV, malaria or TB. A composite index was generated for each type of service provision by summing the value of the respective binary variables (online supplementary section 1).

\section{Measuring funding}

The DHSST has variables indicating the amount of funds received directly from foreign donors, government and other sources. Funds from non-donor sources, such as government investments, could also include donors' disbursements to the government. Health centres, however, did not have information on the source of the government funds received and only reported the total value of funds directly received from the government. Given that we were not able to distinguish between government funding originating from aid or the domestic public spending, the focus of this study is on the direct cash contribution from donors and governments. All the funding variables are converted to constant 2009 US\$.

\section{Covariates}

To understand if aid affected two types of rural healthcare centre differently, we included a binary variable, indicating the exclusive government ownership of a rural health centre. We also included a variable, percentage of indigent population in the catchment area of a health centre, in the regressions as a proxy of income level in the catchment area of a health centre. A high percentage indicates more poor residents living in the catchment area. The DHSST does not have other variables that could be used to indicate income level in the catchment area of a health centre. Year and district indicators were used in regressions to adjust for unobserved secular trends and heterogeneity across districts.

Summary statistics of these variables are presented in online supplementary appendix table 2 .

\section{Statistical analysis}

On aid additionality

We performed regression analysis using per capita funds from the government in log terms as the dependent variable and per capita aid in log terms as the independent variable. We included per capita fund from other sources to control for its effect on government investments. Other covariates included ownership type, indigent population and year indicators. Because of decentralisation, health centres in the same district were more likely to be similar. We used multilevel (three-level) mixed-effects model 
to capture four sources of variation in the government investments: health-centre-level factors, health-centrelevel clustering effects, district-level clustering effects and random effects (online supplementary section 2). ${ }^{29}$

\section{On association between aid and service provision}

We regressed the service provision index on per capita aid in $\log$ terms using three-level mixed-effects model as above. To control for effects from non-aid funds, we included per capita non-aid funds in the analysis. Other covariates were the same as the additionality analysis (online supplementary section 2 ).

\section{Sensitivity analysis}

Analyses with alternative model specifications and estimation methods were undertaken to check the robustness of the findings. Specifically, we looked at three issues in detail: (1) sensitivity to the mathematical transformation of service provision variables, (2) sensitivity to estimation methods (ie, using a fixed-effects model (at the health centre level) that generate less biased estimates ${ }^{30}$ ) and (3) sensitivity to the assumption about the timing of aid effects on service provision or government investments (online supplementary section 3 and online supplementary appendix table 3 ).

STATA V.14 was used for all statistical analyses.

\section{RESULTS \\ Additionality of foreign aid in rural healthcare centres}

Trends between 2009 and 2011 (table 1) revealed that both donors and governments increased their investments in the health centres: donors' contributions to the 330 rural health centres almost doubled, from US $\$ 5.8$ million (19\% of total funds) in 2009 to 11.3 million (28\% of total funds) in 2011. The Rwandan government allocated approximately US $\$ 8.9$ million, US $\$ 10.5$ million and US $\$ 12.5$ million to the 330 health centres in 2009 , 2010 and 2011, respectively, corresponding to 30\%, 29\% and $31 \%$ of all received funds. During the 3-year period, government remained the largest financial contributor to the health centres, followed by foreign donors in 2010 and 2011 (online supplementary appendix figure 1). The trends of per capita funds from donors and governments during the period revealed a similar finding. A total of $61 \%$ of the 330 rural health centres were owned by the government exclusively (online supplementary appendix table 2), and the upward trends in funds from donors or governments held for both types of facilities.

Assuming that there is no time lag in the government's funding decision in response to donor contributions, the regression results in table 2 suggest that donor contributions were positively associated with the receipt of government funds. When using three-level mixed-effects model, a 10\% increase in average per capita aid was associated with a $1.3 \%$ increase in the average per capita value of received government funds. In other words, increasing average aid per capita by US $\$ 1$ was linked to US $\$ 0.17$ increase in government spending in the same year.
Table 1 Total and per capita funds (in 2009 US\$) received from donors and governments in the 330 rural health centres and by ownership, 2009-2011

\begin{tabular}{|c|c|c|c|}
\hline & 2009 & 2010 & 2011 \\
\hline \multicolumn{4}{|c|}{ Funds received from donors } \\
\hline Total & 5804118 & 8187399 & 11276213 \\
\hline $\begin{array}{l}\text { Government } \\
\text { ownership }\end{array}$ & 3377188 & 4971323 & 6413073 \\
\hline $\begin{array}{l}\text { NGOs/FBOs } \\
\text { ownership }\end{array}$ & 2426930 & 3216076 & 4863141 \\
\hline \multicolumn{4}{|c|}{ Funds received from governments } \\
\hline Total & 8867868 & 10452180 & 12526954 \\
\hline $\begin{array}{l}\text { Government } \\
\text { ownership }\end{array}$ & 5275512 & 6308628 & 7722877 \\
\hline $\begin{array}{l}\text { NGOs/FBOs } \\
\text { ownership }\end{array}$ & 3592356 & 4143553 & 4804077 \\
\hline \multicolumn{4}{|c|}{ Per capita funds from donors } \\
\hline Total & 0.82 & 1.16 & 1.60 \\
\hline $\begin{array}{l}\text { Government } \\
\text { ownership }\end{array}$ & 0.79 & 1.17 & 1.48 \\
\hline $\begin{array}{l}\text { NGOs/FBOs } \\
\text { ownership }\end{array}$ & 0.87 & 1.13 & 1.79 \\
\hline \multicolumn{4}{|c|}{ Per capita funds from governments } \\
\hline Total & 1.25 & 1.48 & 1.78 \\
\hline $\begin{array}{l}\text { Government } \\
\text { ownership }\end{array}$ & 1.23 & 1.49 & 1.79 \\
\hline $\begin{array}{l}\text { NGOs/FBOs } \\
\text { ownership }\end{array}$ & 1.29 & 1.46 & 1.77 \\
\hline
\end{tabular}

FBO, faith-based organisation; NGO, non-governmental organisation.

The results remained stable when using a fixed-effects model. We did not find a significant association between government investments in the current year and aid in the previous year (coefficient -0.002 with SE 0.03 ). The results remained stable when using fixed-effects model.

The average service provision index for child and maternal care across the 330 rural health centres has increased from 24.45 (36\% of 67 services) in 2009 to 38.63 (58\% of 67 services) in 2011 (table 3 ). The average index of services provided for HIV, TB and malaria has increased from 10.73 (35\% of 31 services) in 2009 to 20.62 (67\% of 31 services) in 2011. The upward trend held for both types of facility ownership.

When assuming aid affected health service provision in the year of receiving aid, we did not find a significant association between service provision index and donor funds (online supplementary appendix table 4). However, we found a positive association between service provision index and donor funds received in the previous year (table 4). When using multilevel mixed-effects model and service provision index for child and maternal care in log terms, the coefficient of per capita aid in log terms is 0.008 and is statistically significant. This indicates that 
Table 2 Estimated coefficients of per capita fund from donors in additionality analysis (data sources: DHSST)

\begin{tabular}{|c|c|c|}
\hline & $\begin{array}{l}\text { Multilevel random } \\
\text { effects }^{\dagger}\end{array}$ & Fixed effects ${ }^{\ddagger}$ \\
\hline $\begin{array}{l}\text { Log (per capita } \\
\text { funds from } \\
\text { government) }\end{array}$ & Coefficients (SE) & Coefficients (SE) \\
\hline \multicolumn{3}{|c|}{ Assuming aid effects in the same year } \\
\hline $\begin{array}{l}\text { Log (per capita } \\
\text { funds from } \\
\text { donors) }\end{array}$ & $0.13^{\star \star \star}(0.033)$ & $0.14^{\star \star \star}(0.041)$ \\
\hline Observations & 990 & 990 \\
\hline \multicolumn{3}{|c|}{$\begin{array}{l}\text { Assuming aid with 1-year lagged } \\
\text { effects }\end{array}$} \\
\hline $\begin{array}{l}\text { Log (per capita } \\
\text { funds from)__ } \\
\text { Lagged }\end{array}$ & $-0.002(0.03)$ & $-0.07(0.05)$ \\
\hline Observations & 660 & 660 \\
\hline
\end{tabular}

${ }^{* * *}$ Statistically significant at the 0.01 level.

†Clustering effects at the health centre and district levels.

$\ddagger$ Fixed effects at the health centre level.

DHSST, District Health System Strengthening Tool.

a $10 \%$ increase in average aid per capita in the previous year is associated with a $0.08 \%$ increase in the average service provision index in the current year, holding everything else constant. The positive association was also found when using the service provision index of the infectious diseases: a $10 \%$ increase in average aid per capita in the previous year is associated with a $0.14 \%$ increase in the average service index of infectious diseases in the current year, holding everything else constant. On average, increasing aid per capita by US $\$ 1$ in the previous year was associated with a 0.18 or 0.15 unit increase of the service index for child or maternal health and for infectious diseases in the current year, respectively.

Table 3 Average service provision index across the 330 rural health centres and by ownership, 2009-2011

\begin{tabular}{|c|c|c|c|}
\hline & 2009 & 2010 & 2011 \\
\hline \multicolumn{4}{|l|}{$\begin{array}{l}\text { Mean index of child and } \\
\text { maternal care }\end{array}$} \\
\hline Total (330) & 24.45 & 26.82 & 38.63 \\
\hline Government owned (202) & 23.6 & 26.3 & 38.2 \\
\hline $\begin{array}{l}\text { NGOs/FBOs ownership } \\
\text { (128) }\end{array}$ & 25.8 & 27.7 & 39.3 \\
\hline \multicolumn{4}{|l|}{$\begin{array}{l}\text { Mean index of HIV, TB and } \\
\text { malaria care }\end{array}$} \\
\hline Total (330) & 10.73 & 10.79 & 20.62 \\
\hline Government owned (202) & 10.65 & 10.65 & 20.50 \\
\hline $\begin{array}{l}\text { NGOs/FBOs ownership } \\
\text { (128) }\end{array}$ & 10.86 & 11.02 & 20.82 \\
\hline
\end{tabular}

FBO, faith-based organisation; NGO, non-governmental organisation; TB, tuberculosis.
Table 4 Estimated coefficients of per capita funds from donors in service provision analysis by assuming 1-year lagged aid effects in the 330 rural health centres (data sources: DHSST)

Coefficients of per capita funds from donors (SE)

\begin{tabular}{|c|c|c|}
\hline & $\begin{array}{l}\text { Multilevel mixed } \\
\text { effects } \dagger\end{array}$ & Fixed effects $¥$ \\
\hline \multicolumn{3}{|c|}{ Index of child and maternal care (CMindex) } \\
\hline \multicolumn{3}{|l|}{ Log (CMindex) } \\
\hline $\begin{array}{l}\text { Log (per capita } \\
\text { funds from } \\
\text { donors)_Lag }\end{array}$ & $0.008(0.003)^{\star \star}$ & $0.007(0.004)^{*}$ \\
\hline \multicolumn{3}{|l|}{ CMindex } \\
\hline $\begin{array}{l}\text { Log (per capita } \\
\text { funds from } \\
\text { donors)_Lag }\end{array}$ & $0.26(0.08)^{\star \star \star}$ & $0.27(0.13)^{\star \star}$ \\
\hline Observations & 660 & 660 \\
\hline \multicolumn{3}{|c|}{ Index of HIV, TB and malaria care (HTMindex) } \\
\hline \multicolumn{3}{|l|}{ Log (HTMindex) } \\
\hline $\begin{array}{l}\text { Log (per capita } \\
\text { funds from } \\
\text { donors)_Lag }\end{array}$ & $0.014(0.004)^{\star \star \star}$ & $0.01(0.005)^{\star}$ \\
\hline \multicolumn{3}{|l|}{ HTMindex } \\
\hline $\begin{array}{l}\text { Log (per capita } \\
\text { funds from } \\
\text { donors)_Lag }\end{array}$ & $0.18(0.06)^{\star \star \star}$ & $0.11(0.07)$ \\
\hline Observations & 660 & 660 \\
\hline
\end{tabular}

*Statistically significant at the 0.1 level.

** Statistically significant at the 0.05 level.

${ }^{* * *}$ Statistically significant at the 0.01 level.

†Clustering effects at the health centre and district levels.

†Fixed effects at the health centre level.

DHSST, District Health System Strengthening Tool; TB, tuberculosis.

The positive association between aid in the previous year and the service provision index for child and maternal health in the current year was robust when using service provision indices in real terms and fixed-effects models (table 4 ). The positive association between aid and the service provision for the three infectious diseases was robust when using fixed-effects model but sensitive to its scale change (table 4). Regression results with all variables are presented in online supplementary appendix tables 5-7.

\section{DISCUSSION}

In Rwanda, an increase in foreign aid did not appear to have crowded out government investments and was positively associated with service provision for child and maternal care and infectious diseases in the coming year in the rural health centres. The panel data were obtained from 330 rural health centres between 2009 and 2011 in Rwanda. These results are robust to the choice of scales 
of the dependent variables and estimation methods but sensitive to the assumption of timing of aid effects. One possible explanation for no significant association between aid received in the previous year and the government investments in the current year is that the decision of the GoR on investing in health centres was not affected by the donors' contribution to health centres in previous years.

The study suggests that GoR did not respond to the inflow of foreign aid by cutting back their investments in rural healthcare centres, which is consistent with the commitment of the GoR to strengthening the rural healthcare delivery system. At the national level, the percentage of government spending on health (including aid) increased from $9 \%$ in 2000 to $24 \%$ in $2011,{ }^{1}$ making Rwanda one of the four countries in 2011 that achieved the target of the Abuja Declaration-devoting 15\% or more of their yearly budgets to health sector. ${ }^{31}$ The available data show that per capita domestic public spending on health remained at US\$7 in 2003 and 2006 as the contribution of foreign aid to the health sector increased from $42 \%$ in 2003 to $53 \%$ in 2006 .

At the subnational level, our results on relative contributions of donors and governments contrast sharply with a publication that examined the funding sources for two rural Rwanda provinces in 2002. The authors reported that $60 \%$ of the total budget in rural health centres was supported by donors, $35 \%$ by household and only $4 \%$ by the government. ${ }^{15}$ In our study, the government was the largest financial contributor to rural health centres over the 3-year period, and external donors and individual households accounted for much smaller shares than they did in the 2002 results. The apparent large increase in government funds and a significant reduction in household out-of-pocket health spending suggest a substantial improvement in long-term financial sustainability in rural healthcare centres and less financial burden on households, both of which are important steps towards universal healthcare. In addition, as previously noted, government funds received by health centres could include foreign aid provided to higher-level agencies within the Rwandan government, and we were not able to distinguish between government funds that originated from foreign donors and government funds originating from within the Rwanda treasury. The increase of foreign aid at the higher level could thus be an indirect driving force for the increase of government funds at the health centre level.

The findings of positive associations between aid in the previous year and service provision indices in the current year and no association between aid and service provision in the same year suggest that it took time for aid to be effective in making service available in the rural health centres for both infectious diseases and child and maternal care. Although there was no significant difference in service provision between government-owned and $\mathrm{FBO} / \mathrm{NGO}$-owned health centres, we observed a large increase, from 2010 to 2011, in service provision indices for both types of services because of an increased availability of clinical services on malnutrition, newborn and pregnancy, HIV, TB and malaria in the rural health centres. These findings, in a broader sense, are consistent with the take-off of a wide range of policy initiatives and interventions at the national and community levels for improving child and maternal health, controlling HIV and $\mathrm{TB}$ and eradicating malaria during the period. In 2010, for example, the National Emergency Programme to Eliminate Malnutrition was implemented to address chronic malnutrition with a community-based nutritional intervention approach in health centres. ${ }^{32}$ A national strategic plan on HIV and AIDS from 2009 to 2012 set up a target that all health centres should provide complete HIV services (voluntary counselling and testing/prevention of mother-to-child transmission/antiretroviral therapy) ${ }^{33}$ Foreign donors played an important role in financing these interventions and policy initiatives. ${ }^{34}$ In 2009 or 2010, many of these policy instruments were in the early stages of roll-out. After 1 or 2 years of implementation with financial support from the governments and donors, rural healthcare centres in 2011 were more ready to provide the required services.

\section{Implications}

Each year, millions of dollars of foreign aid are poured into the health sectors of low-income countries. With increasing decentralisation, this aid is becoming more likely to flow directly to the subnational level, and possibly even the facility level. Despite the intensive debates over aid effectiveness, the existing literature offered little empirical evidence regarding the interplay between aid, government investments and service provision at the local healthcare facility level. Although national-level studies on aid are important, they are far from sufficient if the goal is to understand how aid is contributing to health system strengthening and population health outcomes. This requires research on local health facilities-the places from which the majority of populations received their primary care. Subnational analysis on aid is especially important for promoting aid transparency when a large proportion of aid that goes directly to local health facilities is often not documented in a country's National Health Accounts. ${ }^{35}$ According to a report from the Rwandan MoH, about $40 \%$ of funding was off-budget. ${ }^{36}$

This study fills a knowledge gap by providing evidence of aid additionality and the link between aid and service provision in rural healthcare centres. Rwanda's success in using a combination of aid and domestic resources to achieve health-related MDGs is worthy of further investigation. Examining this success story may have important policy significance at least in the following aspects.

First, as an important indicator of a government's commitment to public health, government spending in the health sector is crucial for achieving universal health coverage. In Rwanda, as the level of aid increased at both the national and the local levels, government investments to rural health centres have been constantly increasing. 
Although the DHSST did not offer useful information on how aid was allocated to health centres in Rwanda, there were several potential explanations. (1) It could be due to a strong financial commitment from the GoR to strengthening healthcare delivery in rural areas. No matter if a health centre received aid or not, the government kept its commitment in financing rural health centres. (2) It is plausible that donors consulted with the government and/or health centres before allocating funds to health centres and ensured that they had the same priorities.

Second, this empirical analysis was made possible by the GoR's commitment to health information transparency for the effective monitoring and evaluation of healthcare financing at the different tiers. The lack of capacity to track and use quality financial data for informed policy making is a challenge faced by many low-income countries. While investing in disease prevention and treatment is important, building up an effective health information system in local health facilities is equally important. Although still among the poorest countries in the world, with donor support, Rwanda has continuously invested in improving health information systems for results-based resource allocation and has taken a lead in adopting district-level health information systems among sub-Saharan countries. ${ }^{27}{ }^{37}$ Developing a clear set of reporting standards and easy-to-implement data tracking systems for resources and service provision at the local health facility level will help both donors and governments to effectively coordinate on budgeting, monitoring and evaluating aid performance. It will also enable countries to learn from the experiences of others.

Third, integrating aid, government investments and other funding sources is crucial for improving service availability in rural health centres and supporting a stronger local health system. It is important to have close collaboration between policy makers, at both national and local levels, and external donors when developing a sustainable financial plan for strengthening local health facilities. Health priorities at both national and local levels should be taken into consideration when foreign donors design their projects.

Using the DHSST data, this study investigated if crowd-out effect occurred at the rural health centre level. Moving forward, to help inform both donors and policy makers with more evidence on developing best practices for aid effectiveness, it will be necessary to go beyond our association analysis and focus on remaining issues such as (1) at the healthcare facility level, how donors and local health leaders make decisions on how much to invest, for how long and on which services in rural healthcare centres, and if there was any involvement from communities in the decision-making process, and (2) at the population level, if aid to health centres affected the use of medical care services, equal access to healthcare and health outcomes. As rural health centres in Rwanda play a key role in delivering most preventive and promotional services through community health worker programmes, we especially want to investigate donors' support to the community health workers and the effect of community health workers on medical care utilisation by rural residents.

\section{Limitations}

First, we were not able to identify causality due to potential endogeneity between aid, government health investments and service provision. For example, economic shocks in both recipient and donor countries could lead to a rise or fall in their investments. Changes in the priorities of donors or the Rwandan government could also affect their budget decision and investing targets. Second, given a lack of appropriate data, we were not able to identify the effect of aid on population health outcomes. Third, we only have panel data for 3 years, which did not allow us to investigate aid effects across a longer time period. Fourth, our service provision variables were not able to capture the quality and frequency of a service offered by a health centre. Fifth, due to the issue of data availability, the study did not include in-kind support, a considerable portion of health centre expenditures. ${ }^{27}$

\section{CONCLUSION}

Using novel local-level data on finance and services in rural health centres, this study found a significant positive link between foreign aid and government investments in the rural health centres in Rwanda, and a significant positive association between aid in the previous year and service provision in the current year. Our findings therefore suggest that aid could significantly affect the supply of health services in the poorest rural areas when it is additional to government investments. Ensuring aid additionality should be given high priority when designing policy instruments for achieving aid effectiveness.

Acknowledgements We thank Yiqun Luan for his valuable research assistance.

Contributors CL conceived and designed the study, led statistical analysis and wrote the first draft. BC and CD contributed to study design. All the authors participated in results interpretation and manuscript writing.

Funding This study was funded by NIH 1KOHD07 1929-01.

Competing interests None declared.

Provenance and peer review Not commissioned; externally peer reviewed.

Data sharing statement Data can be obtained through application to the Ministry of Health in Rwanda.

Open Access This is an Open Access article distributed in accordance with the Creative Commons Attribution Non Commercial (CC BY-NC 4.0) license, which permits others to distribute, remix, adapt, build upon this work non-commercially, and license their derivative works on different terms, provided the original work is properly cited and the use is non-commercial. See: http://creativecommons.org/ licenses/by-nc/4.0/

(C) Article author(s) (or their employer(s) unless otherwise stated in the text of the article) 2017. All rights reserved. No commercial use is permitted unless otherwise expressly granted.

\section{REFERENCES}

1. World Health Organization (2014) Global Health Expenditure Database. Geneva: World Health Organization. http://apps.who.int/ nha/database (accessed 7 Oct 2016). 
2. Khaleghian P. Decentralization and Public Services: The Case of Immunization. Washington DC: World Bank, 2003. http://www1. worldbank.org/publicsector/decentralization/Feb2004Course/ Background\%20materials/Khaleghian.pdf (accessed 24 Oct 2014).

3. Bossert TJ, Larrañaga O, Giedion U, et al. Decentralization and equity of resource allocation: evidence from Colombia and Chile. Bull World Health Organ 2003;81:95-100.

4. Berlan D, Shiffman J. Holding health providers in developing countries accountable to consumers: a synthesis of relevant scholarship. Health Policy Plan 2012;27:271-80.

5. Lu C, Michaud CM, Khan K, et al. Absorptive capacity and disbursements by the Global Fund to Fight AIDS, Tuberculosis and Malaria: analysis of grant implementation. Lancet 2006;368:483-8.

6. Lu C, Michaud CM, Gakidou E, et al. Effect of the Global Alliance for vaccines and immunisation on diphtheria, tetanus, and pertussis vaccine coverage: an Independent assessment. Lancet 2006;368:1088-95.

7. Lu C, Schneider MT, Gubbins P, et al. Public financing of health in developing countries: impact of GDP growth, size of government and development assistance for health. Lancet 2010;375:1375-87.

8. Garg CC, Evans DB, Dmytraczenko T, et al. Study raises questions about measurement of 'additionality, 'or maintaining domestic health spending amid foreign donations. Health Aff 2012;31:417-25.

9. Gilbert BJ, Patel V, Farmer PE, et al. Assessing development assistance for mental health in developing countries: 2007-2013. PLoS Med 2015;12:e1001834.

10. Greco G, Powell-Jackson T, Borghi J, et al. Countdown to 2015: assessment of donor assistance to maternal, newborn, and child health between 2003 and 2006. Lancet 2008;371:1268-75.

11. Pitt C, Greco G, Powell-Jackson T, et al. Countdown to 2015: assessment of official development assistance to maternal, newborn, and child health, 2003-08. Lancet 2010;376:1485-96.

12. Hsu J, Pitt C, Greco G, et al. Countdown to 2015: changes in official development assistance to maternal, newborn, and child health in 2009-10, and assessment of progress since 2003. Lancet 2012;380:1157-68.

13. Schäferhoff M, Schrade C, Yamey G. Financing maternal and child health - what are the limitations in estimating donor flows and resource needs? PLoS Med 2010;7:e1000305.

14. Van de Sijpe N. Is Foreign Aid Fungible? Evidence from the education and Health Sectors. World Bank Econ Rev 2013;27:320-56.

15. Kalk A, Kagubare MJ, Musango L, et al. Paying for health in two rwandan provinces: financial flows and flaws tropical medicine and International Health. , 2005:10, 872-8.

16. World Bank. World Development Indicators. Rwanda: GDP per capita (constant 2010US\$. Washington, DC: World Bank.

17. National Institute of Statistics of Rwanda. The fourth integrated household living conditions survey (EICV 4). Kigali: National Institute of Statistics, 2015. http://www.statistics.gov.rw/publication/rwandapoverty-profile-report-results-eicv-4 (accessed 16 Nov 2016)

18. National Institute of Statistics of Rwanda. http://www.statistics.gov. $\mathrm{rw} /$ survey/districts-baseline-survey

19. National Institute of Statistics of Rwanda (NISR) [Rwanda], Ministry of Health (MOH) [Rwanda], and ICF International. Rwanda Demographic and Health Survey 2014-15. Rockville, Maryland, USA: NISR, MOH, and ICF International, 2015.

20. UNICEF and World Health Organization. "A decade of tracking progress for maternal,newborn and child survival: the 2015 report".
2015 http://www.countdown2015mnch.org/reports-and-articles/ 2015-final-report (accessed 8 Apr 2016).

21. Antunes AF, Saksena P, Elovainio R, et al. Health Financing Systems Review of Rwanda: options for universal coverage. Geneva: World Health Organization and Republic of Rwanda Ministry of Health, 2009.

22. Ministry of Health of Rwanda. Rwanda annual health statistics booklet 2014. Kigali: Ministry of Health, 2015. http://moh.gov.rw/ fileadmin/templates/HMIS_Docs/MOH_Statistical_Booklet_2014.pdf (accessed 16 Nov 2016)

23. Mejía-Guevara I, Hill K, Subramanian SV, et al. Service availability and association between Mutuelles and medical care usage for under-five children in rural Rwanda: a statistical analysis with repeated cross-sectional data. BMJ Open 2015:5:e008814.

24. National Institute of Statistics of Rwanda (NISR) [Rwanda], Ministry of Health (MOH) [Rwanda], and ICF International. Rwanda Demographic and Health Survey 2010. Calverton, Maryland, USA: NISR, MOH, and ICF International, 2012.

25. Ministry of Health of Rwanda. Health Sector Policy 2015. Kigali: Ministry of Health or Rwanda, 2015. http://www.moh.gov.rw/ fileadmin/templates/policies/Health_Sector_Policy___19th_ January_2015.pdf

26. Rwanda Ministry of Health. Rwanda Health Statistics 2010. Kigali: Ministry of Health, 2011.

27. Lu C, Tsai S, Ruhumuriza J, et al. Tracking rural health facility financial data in resource-limited settings: a case study from Rwanda. PLoS Med 2014;11:e1001763.

28. National Institute of Statistics of Rwanda. Statistical Year Book 2012. Kigali: Ministry of Health, 2013.

29. Rasbash J, Steele F, Browne WJ, et al. A User's Guide to MLwiN. Version 2.26. Bristol, UK: Centre for Multilevel Modeling, University of Bristol, 2012.

30. Wooldridge JM. Introductory econometrics: a modern approach. 5th ed. Mason, OH: South-Western, 2013:466-78.

31. World Health Organization. The Abuja declaration: 10 years on. http://www.who.int/healthsystems/publications/Abuja10.pdf (accessed 5 Jan 2017).

32. National Multi-Sectoral Strategy to eliminate malnutrition. Kigali: Rwanda Ministry of Health, 2010.

33. Office of the President National AIDS control commission. National Strategic Plan on HIV \& AIDs 2009-2012. http://www.ilo.org/ wcmsp5/groups/public/-ed_protect/-protrav/-ilo_aids/documents/ legaldocument/wcms_127584.pdf

34. Lu C, Mejía-Guevara I, Hill K, et al. Association between communitybased health financing approach and child stunting in Rural Rwanda: an Observational study. American Journal of Public Health 2016:106:49-55.

35. Van de Sijpe N. Is Foreign Aid Fungible? Evidence from the Education and Health Sectors. World Bank Econ Rev 2013;27:320-56.

36. Ministry of Health. Rwanda Health Resource Tracker: output Report. 2013 http://www.moh.gov.rw/fileadmin/templates/MOH-Reports/ HRT_annual_report_2012_13.pdf (accessed 9 Nov 2016).

37. Rwanda Ministry of Health. Rwanda hailed for good use of Health Information Systems. Kigali, Rwanda: Ministry of Health, 2014 http://www.moh.gov.rw/index.php? id=34\&tx_ttnews\%5Btt news $\% 5 \mathrm{D}=475 \& \mathrm{cHash}=\mathrm{f} 6785 \mathrm{fd} 10 \mathrm{cab} 6 \mathrm{~d} 484847 \mathrm{a} 20062417185$ (accessed 7 Jun 2014). 